\title{
Boletín Criminológico
}

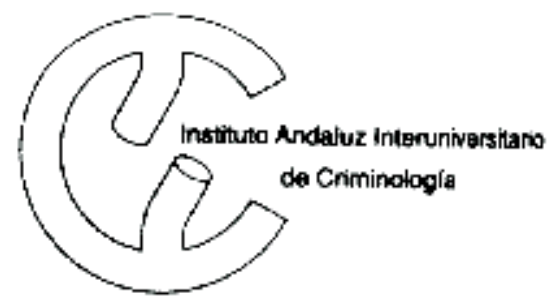

Directora: Per Stangeland.

Coordinadora: Elisa García España

Publicado por la Sección de Málaga del IAIC

Facultad de Derecho, Universidad de Málaga

Campus de Teatinos, 29071 MALAGA

El mayor peligro de sufrir una muerte violenta e intencionada reside en uno mismo: hay ocho suicidios por cada homicidio. En segundo lugar el peligro surgirá de las personas que tengamos más cerca: marido, ex-marido, padres o hijos. En tercer lugar vienen los amigos y conocidos y en el cuarto lugar, como posibilidad ya más remota, una persona desconocida.

Estas tragedias no se parecen mucho a lo que vemos en las películas. Los motivos suelen ser muy simples, el ambiente donde se desarrollan muy humilde, y el autor fácil de identificar.

Los criminólogos tendrían escasas posibilidades de empleo si se dedicasen básicamente a aclarar homicidios: no hay más que ocho homicidios de promedio al año en la ciudad de Málaga. La tasa de homicidios es moderada, comparable con la media española, y confirma lo ya deducido por otros indicadores de que España es un país poco violento: Las cifras de homicidios y otros delitos violentos son más bajas que en los países de nuestro entorno, más bien al nivel de los países escandinavos.

\section{HOMICIDIOS EN LA CIUDAD}

\section{DE MÁLAGA}

\section{METODOLOGÍA}

Los datos respecto a la edad, sexo y causa de la muerte de cada víctima de los homicidios fueron extraídos de las fichas de las autopsias judiciales de la cátedra de Medicina Legal de la Universidad de Málaga. Las características geográficas y temporales, el móvil, armas e instrumentos utilizados, así como la relación existente entre víctima y agresor, se obtuvieron de las diligencias policiales del Grupo de Homicidios del Cuerpo Nacional de Policía de la Comisaría Provincial de Málaga. Las tasas de homicidios, por habitantes y edades, se calcularon utilizando el censo de 1991 facilitado por el Instituto Nacional de Estadística y contrastado con el padrón municipal.

\section{INTRODUCCIÓN}

Autores:

Guerrero Checa, A Santos Amaya, I.M

Durante los últimos siete años, desde 1988 a 1994, ocurrieron en Málaga capital un total de 50 homicidios consumados, incluyendo en ellos los tipos penales de homicidio simple, parricidio, asesinato e infanticidio, sin contar las formas imperfectas de ejecución (tentativa y frustración).

Málaga es una ciudad costera y turística, de una extensión de 393 kilómetros cuadrados y con una población de 531.443 habitantes. Según datos policiales, ocupa el quinto lugar entre las capitales de provincia en el número de delitos conocidos.

\section{RESULTADOS}

Málaga capital tiene una media anual de homicidios de 1,3 por cada cien mil habitantes, cifra que se ha mantenido relativamente estable a través de los años del estudio, a excepción de 1991 donde aumenta como consecuencia de un homicidio múltiple (tres fallecidos). La mayoría de las víctimas son varones (en una relación de 4 por cada mujer). Los grupos de edades más frecuentes, respecto a las víctimas, son los de 25 a 29 y 50 a 54 años, mientras que para los agresores el de 20 a 29 años. El

\section{Boletín Criminológico $N^{o} 11$ Junio 1995 Página 1}




\begin{tabular}{|l|} 
TIPOS DE HOMICIDIOS \\
Entendemos por homicidios en \\
riñas aquéllos que se originan \\
motivados por discusiones re- \\
lativas a dinero o propiedades \\
en general, donde el factor \\
desencade-nante suele ser un \\
insulto o discrepancia. \\
En la categoría de homicidios \\
relacionados con drogas se han \\
incluído los causados por ajus- \\
tes de cuentas entre pequeños \\
traficantes o entre éstos y con- \\
sumidores. \\
Por homicidios en el ámbito \\
doméstico se hace referencia \\
exclusivamente a los homici- \\
dios ocurridos entre familiares \\
o parejas. \\
El homicidio causado como \\
consecuencia de un robo se ha \\
calificado como homicidios \\
por robos. \\
Por último, se entiende por \\
infanticidio la muerte de un \\
recién nacido, por parte de la \\
madre o de los abuelos ma- \\
ternos, para ocultar la des- \\
honra que ocasiona el naci- \\
miento de ese niño.
\end{tabular}

agresor fué identificado en un 90\% de los casos.

Las riñas y discusiones suelen ser los motivos más habituales (véase gráfico sobre tipos de homicidios), y el arma blanca el instrumen

mento lesivo más utilizado. Generalmente agresor y víctima se conocen, resultando el domicilio el lugar más habitual para la comisión del delito.

\section{Homicidios ocurridos en riñas y discusiones}

Este tipo de homicidios representan el 34\% del total (17 casos).

\section{HOMICIDIOS POR AÑOS}

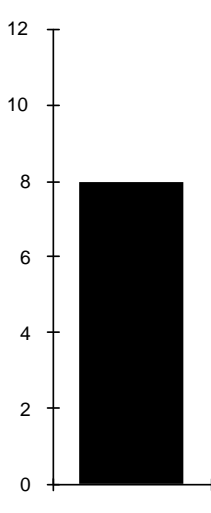

1988

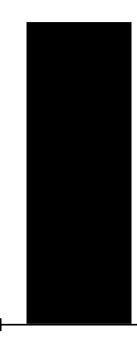

1989

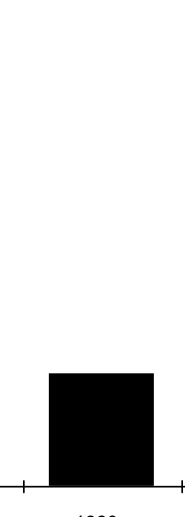

1990

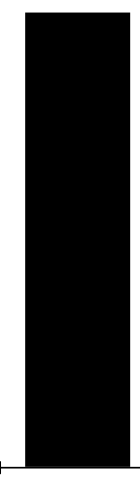

1991

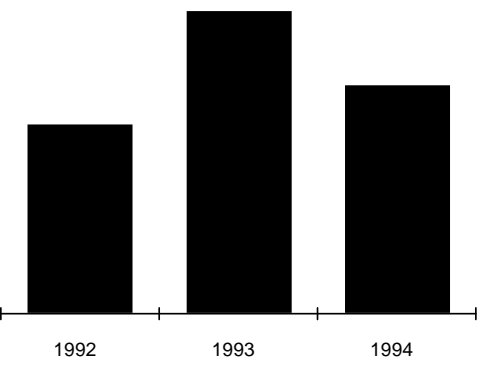

cuentas entre pequeños traficantes o entre éstos y consumidores. Estos crímenes suelen ocurrir en las barriadas marginales de nuestra capital, conocidos lugares de venta de drogas (vía pública o domicilio del vendedor o consumidor). Mayoritariamente las víctimas son varones jóvenes de edades comprendidas entre los $25 \mathrm{y}$ 29 años. El empleo de armas de fuego resulta en estos casos habitual.

Durante los años analizados sólo se produjeron dos homicidios múltiples, de los cuales el que se

\section{Homicidios relacionados con la droga}

El 28\% de los homicidios registrados (un total de 14 casos) estuvo motivado por ajustes de

\section{TIPO DE HOMICIDIOS}

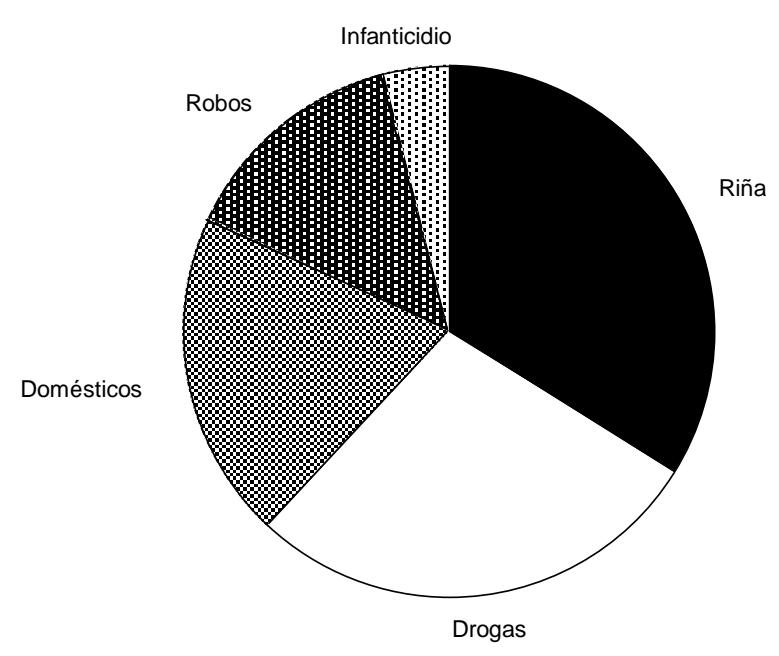

Boletín Criminológico $N^{o} 11$ Junio 
cometió en 1988 estaba relacionado con la droga, saldándose con tres víctimas mortales por parte de un mismo agresor.

\section{Homicidios en el ámbito do- méstico}

El 24\% de los homicidios se producen en el ámbito doméstico (12 casos), ocupando el tercer lugar en importancia. El agresor suele ser una persona cercana a la víctima: novio/a, pareja de hecho o pareja anterior. Los motivos desencade-nantes suelen ser pasionales o disputas entre familiares. En dos de los casos estudiados el agresor se suicidó tras consumar el delito. En los casos analizados no existen diferencias en relación al sexo de las víctimas, dándose una misma proporción entre varones y mujeres; el grupo de edad de mayor riesgo se sitúa entre los 50 y 54 años y se utiliza frecuentemente un arma blanca. El lugar de comisión del delito más común dentro del domicilio es el salón-comedor.

En 1991 se produjo el segundo

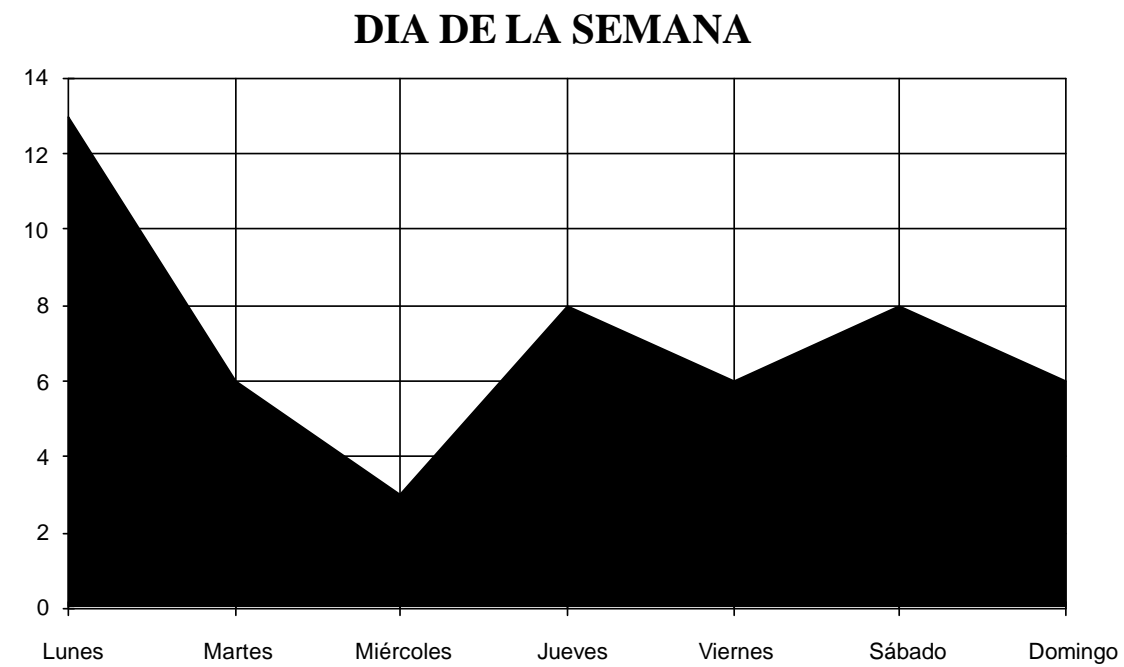

homicidio múltiple del periodo estudiado, debido a una disputa familiar donde el agresor, tras matar a dos hermanos y una hija con varias armas de fuego, se suicidó.

\section{Homicidios por robo}

En nuestro estudio, este tipo de homicidios, representan el 14\% del total (7 casos). El fallecido, generalmente, es un hombre (cinco hombres por dos mujeres), de edad comprendida entre los 60 y 64 años, y el suceso ocurre principalmente en su propio domicilio. Como en otro tipo de homicidios, el instrumento más utilizado es el arma blanca.

\section{Infanticidios}

En el período estudiado ocurieron dos infanticidios en Málaga capital (4\%). En uno de ellos falleció posteriormente la madre.

\section{CONCLUSIONES}

\section{Distribución geográfica}

La mayoría de los homicidios se

\section{EPOCA DEL AÑO}

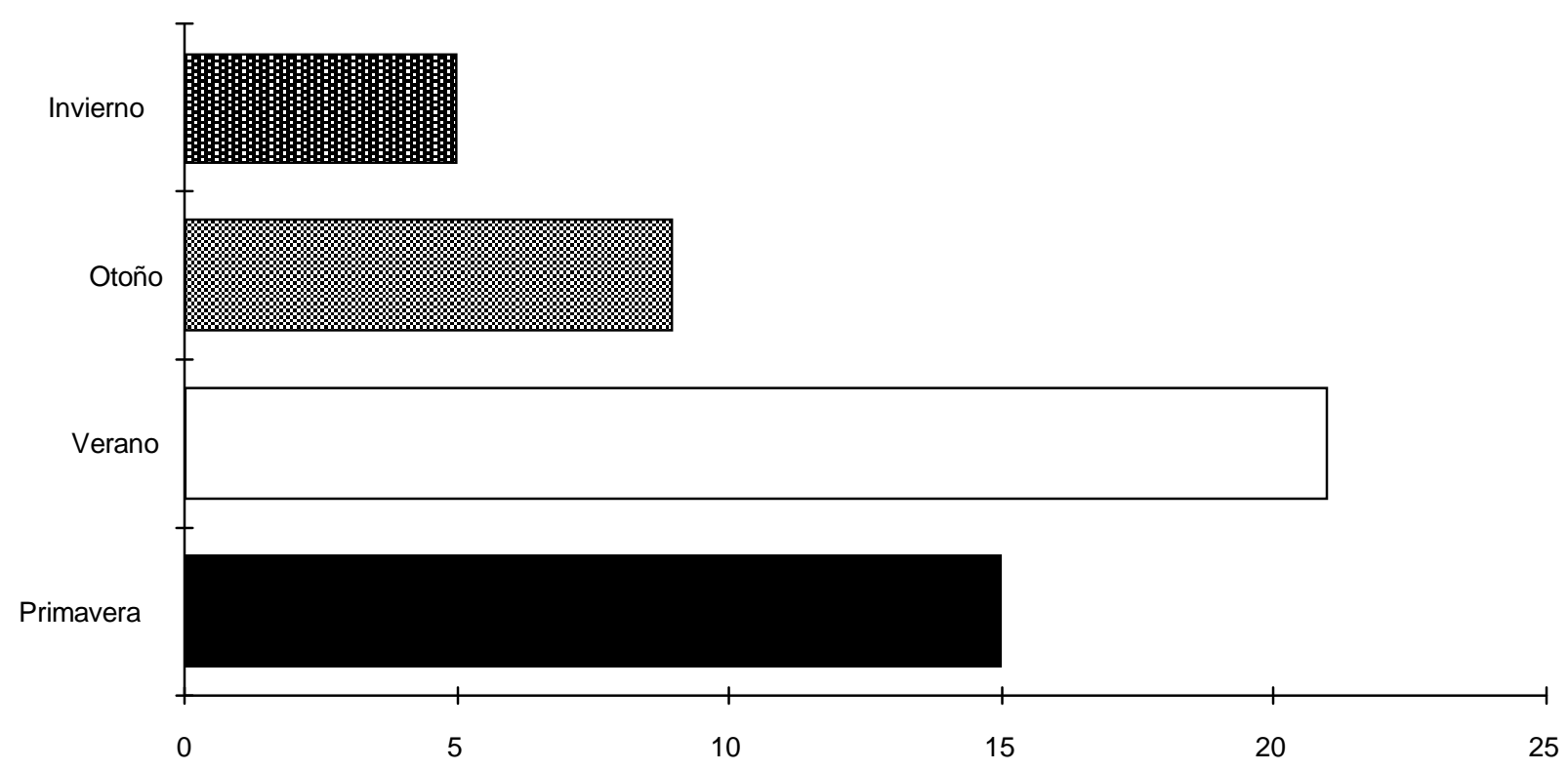

\section{Boletín Criminológico $N^{o} 11 \quad$ Junio 1995 Página 3}


produjeron en ciertas zonas de la capital, en concreto, zona norte (Palma, Palmilla, La Virreina y el 26 de Febrero) y Portada Alta y su prolongación al Camino de Antequera y Trinidad-Perchel.

\section{Día, hora y estación del año}

La mayoría de los homicidios suceden los fines de semana, incluyendo la madrugada del lunes, sobre todo a partir de las 20 horas. En verano y primavera existe un incremento en el número de homicidios (véanse los gráficos de la página 3).

\section{Nacionalidad de las víctimas}

A pesar de ser Málaga una ciudad eminentemente turística, no se ha registrado ninguna víctima extranjera, en contraposición con Torremolinos (a $15 \mathrm{~km}$ ), donde se produjeron, durante el mismo período y con una población próxima a los 32.000 habitantes, 7 víctimas extranjeras.

\section{Consideraciones finales}

El número de homicidios en Málaga capital se ha mantenido relativamente estable en el período analizado y parece afectar a un determinado grupo de riesgo, a saber: españoles, varones, entre 25-29 y 50-54 años.

Ocurren generalmente los fines de semana, noche y madrugada, en barrios populares de la ciudad, con mínima significación en zonas residenciales, y

principalmente en el domicilio.

Estos homicidios se producen frecuentemente entre conocidos. El instrumento más utilizado es el arma blanca debido a su fácil acceso $(78,5 \%)$, aunque se aprecia un aumento de las armas de fuego, sobre todo cor- tas.

Las muertes por homicidios, aunque de gran impacto social, resultan relativamente bajas si las comparamos con otro tipo de muertes violentas ( 8 suicidios por cada homicidio).

La opinión que tiene el público de que los homicidios están asociados con actividades ilegales o delitos debe revisarse, ya que más de la mitad de los casos (57\%) obedecen a riñas, discusiones y peleas familiares o matrimoniales.
Números del Boletín Criminológico publicados hasta la fecha:

1.- Víctimas de delincuencia en Málaga

2.- Discrepancias entre las estadísticas judiciales y policiales

3.- Lentitud de los procesos penales en Málaga

4.- Delincuencia juvenil en Fuengirola.

5.- La legalización de la eutanasia

6.- Turistas extranjeros víctimas de delitos

7.- Llamadas de urgencia a la policía local

8.- Victimización juvenil

9.- Actuaciones policiales en riñas domésticas.

10. - La imagen del delito en la prensa española.

\section{Título de Experto Universitario en Criminología}

El Instituto Andaluz Interuniversitario de Criminología de la Universidad de Málaga imparte sus estuduios de Expero Universitario en Criminología cuya duración es de tres años.

Los interesados deben de haber realizado el primer ciclo de estudios universitarios o bien, teniendo aprobada la selectividad o equivalente, pertenecer a los cuerpos y fuerzas de Seguridad del Estado, Guardia ,Civil, Policía Local, Administración de Justicia, Instituciones Penitenciarias o ser auxiliares de investigador privado.

Todo tipo de información sobre el contenido y estructura del título y las condiciones de ingreso se puede obtener en la secretaría del Instituto (Facultad de Derecho de la Univerasidad de Málaga) Teléfono 2132325

\section{Boletín Criminológico $N^{o} 11 \quad$ Junio 1995 Página 4}

